$\pm N / E$

Global burnals Inc.

है ?

GLOBAL JOURNAL OF MEDICAL RESEARCH: K

INTERDISCIPLINARY

Volume 20 Issue 12 Version 1.0 Year 2020

Type: Double Blind Peer Reviewed International Research Journal

Publisher: Global Journals

Online ISSN: 2249-4618 \& Print ISSN: 0975-5888

\title{
Effect of Alcohol Disinfection on the Handle and Blade of Meat and Fish Knives by using ATP Inspection and Microbial Stamp Test
}

By Akemi Ito, Naomi Katayama, Mayumi Hirabayashi, Natuki Sasaki \& Moe Inuzuka

Nagoya Women's University

Abstract- It is valid to show the cooks a visual hygiene test result to prevent food poisoning. Therefore, in this study, for hygiene control of the handle and blade of frequently used kitchen knives, we report inspections using the ATP wiping test and microbial stamp test. The results of the ATP wiping test showed that the ATP value decreased statistically significantly after washing compared to after cooking, and after $70 \%$ alcohol spraying compared to after washing. A microbial stamp test (general bacteria, Escherichia coli, staphylococcous aureus, Salmonella, Vibrio parahaemolyticus) was also performed at the same time as the ATP test. As a result, the number of bacteria did not change much or decreased even after washing or spraying with $70 \%$ alcohol. In particular, Escherichia coli, staphylococcou aureus were found to be difficult to decrease even after $70 \%$ alcohol sprayings. In the future, it will be necessary to consider increasing the number of alcohol sprays of hygiene management using sodium hypochlorite.

Keywords: ATP test, microbial stamp test, the handle of the knife, the blade of the knife, alcohol disinfection.

GJMR-K Classification: NLMC Code: QW 25.5.M6

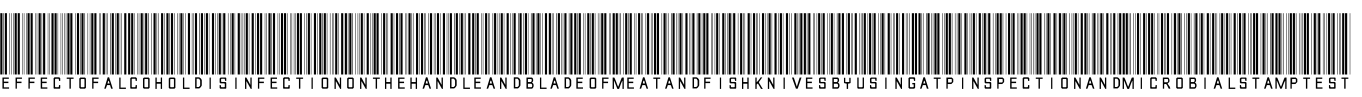

Strictly as per the compliance and regulations of:

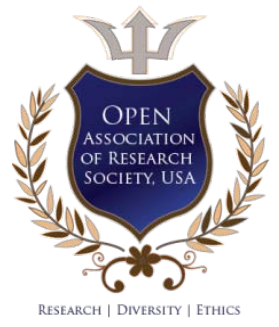

(c) 2020. Akemi Ito, Naomi Katayama, Mayumi Hirabayashi, Natuki Sasaki \& Moe Inuzuka. This is a research/review paper, distributed under the terms of the Creative Commons Attribution-Noncommercial 3.0 Unported License http://creativecommons.org/licenses/by-nc/3.0/), permitting all non-commercial use, distribution, and reproduction in any medium, provided the original work is properly cited. 


\title{
Effect of Alcohol Disinfection on the Handle and Blade of Meat and Fish Knives by using ATP Inspection and Microbial Stamp Test
}

\author{
Akemi Ito ${ }^{\alpha}$, Naomi Katayama ${ }^{\sigma}$, Mayumi Hirabayashi ${ }^{\rho}$, Natuki Sasaki ${ }^{\omega}$ \& Moe Inuzuka ${ }^{*}$
}

\begin{abstract}
It is valid to show the cooks a visual hygiene test result to prevent food poisoning. Therefore, in this study, for hygiene control of the handle and blade of frequently used kitchen knives, we report inspections using the ATP wiping test and microbial stamp test. The results of the ATP wiping test showed that the ATP value decreased statistically significantly after washing compared to after cooking, and after $70 \%$ alcohol spraying compared to after washing. A microbial stamp test (general bacteria, Escherichia coli, staphylococcous aureus, Salmonella, Vibrio parahaemolyticus) was also performed at the same time as the ATP test. As a result, the number of bacteria did not change much or decreased even after washing or spraying with $70 \%$ alcohol. In particular, Escherichia coli, staphylococcou aureus were found to be difficult to decrease even after $70 \%$ alcohol sprayings. In the future, it will be necessary to consider increasing the number of alcohol sprays of hygiene management using sodium hypochlorite.
\end{abstract}

Keywords: ATP test, microbial stamp test, the handle of the knife, the blade of the knife, alcohol disinfection.

\section{INTRODUCTION}

$\mathrm{H}$ ygiene management in the kitchen needs to do daily to prevent food poisoning. The number of food poisoning cases in Japan is high in ordinary households, and the number of victims is high in business establishments. If food poisoning occurs at a school lunch site, it will be a serious situation such as suspension of business, on-site inspection of the health center, transportation of patients to a hospital, and financial security for victims. In some cases, the lunch facility company will be closed, and the lunch service company will force to close. Currently, the kitchen is required to have a more severe sanitary environment due to the COVID-19 epidemic. Therefore, this study focuses on kitchen knives, which are cooking utensils that are highly likely to be involved in food poisoning in the kitchen, and reports the results of the tests using the ATP test and the microbial stamp test. The kitchen knives compared the inspection results on both the handle and the blade.

Author a $\sigma \rho$ : Graduate School of Nagoya Women's University, Nagoya City, Japan.

Author $\sigma \omega ¥:$ Nagoya Women’s University, Nagoya City, Japan.

Author $\sigma$ : Department of Otorhinolaryngology, Nagoya University Graduate School of Medicine, Nagoya, Japan.

Corresponding Author o: Nagoya Women's University, Nagoya City, Japan.e-mail: naomik@nagoya-wu.ac.jp

\section{il. Materials and Methods}

a) Hygiene tests on Kitchen knife

Hygiene tests on six meat and fish knives performed using the ATP test kit (KIKKOMAN CO., Ltd.) and the microbial stamp test kit (NISSUI Co., Ltd.).

b) ATP wiping tests

ATP wiping tests performed on the handles and blades of 6 meat and fish knives. The ATP test was performed by the inspector three times immediately after cooking, after washing, and after spraying $70 \%$ alcohol. The inspector recorded the ATP test results.

\section{c) Microbial stamp test}

And the inspector performed a microbial stamp test as same as ATP tests (three times: after cooking, after washing, and after spraying alcohol). The microbial stamp was then cultured in an incubator at 38 degrees for three days. After culturing, microbial stamps were counted and recorded by the inspector.

\section{d) Statistical processing}

The results obtained compared using statistical methods. Compared data were subjected to an $\mathrm{F}$ test to determine whether to use a parametric test or nonparametric test. When there is no difference in the $\mathrm{F}$ test, the presence or absence of a significant difference was confirmed using the student t-test with or without a correspondence. If there was a difference in the $F$ test, the presence or absence of a significant difference was confirmed using the Wilcoxon test with a pair or the Mann-Whitney test without correlation.

\section{Results}

a) Meat and fish knife: ATP results and microorganisms stamp test results of Alcohol disinfection

ATP test results of kitchen knife handle and blade

The ATP test results show in Table 1 (kitchen knife handle) and Table 2 (kitchen knife blade). In both cases, the ATP value is lower after washing than after cooking, but it did not fall below the target value of 100 . However, after spraying with $70 \%$ alcohol, the ATP value was 100 or less. Alcohol spray can be said to be effective in hygiene management of kitchen knife handle and blade. 


\begin{tabular}{|c|c|c|c|c|}
\hline \multirow[b]{2}{*}{ For meat } & \multicolumn{2}{|c|}{ No alcohol treatment } & \multicolumn{2}{|c|}{ Alcohol treatment } \\
\hline & Before washing & After washing & After washing & After alcohol \\
\hline 1 & 113485 & 5426 & 5426 & 29 \\
\hline 2 & 6915 & 873 & 873 & 41 \\
\hline 3 & 813312 & 18399 & 18399 & 13 \\
\hline 4 & 9631 & 1372 & 1372 & 9 \\
\hline 5 & 10514 & 7055 & 7055 & 36 \\
\hline 6 & 773 & 572 & 572 & 46 \\
\hline Average value & 159105.0 & 5616.2 & 5616.2 & 29.0 \\
\hline SD & 323332.8 & 6803.8 & 6803.8 & 15.1 \\
\hline $\begin{array}{l}\mathrm{F} \text { test } \\
\text { Student-t* }\end{array}$ & \multirow{2}{*}{\multicolumn{2}{|c|}{$\mathrm{P}=0.028 *$}} & \multirow{2}{*}{\multicolumn{2}{|c|}{$\mathrm{P}=0.028 *$}} \\
\hline Wilcoxon & & & & \\
\hline $\begin{array}{l}\mathrm{F} \text { test } \\
\text { Student-t* }\end{array}$ & \multicolumn{4}{|c|}{$\mathrm{P}=0.0001 * *$} \\
\hline Wilcoxon & \multicolumn{4}{|c|}{$\mathrm{P}=0.028 *$} \\
\hline
\end{tabular}

\begin{tabular}{|c|c|c|c|c|}
\hline \multirow[b]{2}{*}{ For meat } & \multicolumn{2}{|c|}{ No alcohol treatment } & \multicolumn{2}{|c|}{ Alcohol treatment } \\
\hline & Before washing & After washing & After washing & After alcohol \\
\hline 1 & 22404 & 247 & 247 & 8 \\
\hline 2 & 96 & 661 & 661 & 12 \\
\hline 3 & 393798 & 2701 & 2701 & 77 \\
\hline 4 & 1125 & 63 & 63 & 63 \\
\hline 5 & 23009 & 4260 & 4260 & 25 \\
\hline 6 & 1638 & 894 & 894 & 30 \\
\hline Average value & 73678.3 & 1471.0 & 1471.0 & 35.8 \\
\hline SD & 157188.5 & 1659.0 & 1659.0 & 28.0 \\
\hline $\begin{array}{l}\mathrm{F} \text { test } \\
\text { Student- } \mathrm{t} *\end{array}$ & \multicolumn{2}{|c|}{$\mathrm{P}=0.0001 * *$} & \multicolumn{2}{|c|}{$\mathrm{P}=0.0001 * *$} \\
\hline Wilcoxon & \multicolumn{2}{|c|}{$\mathrm{P}=0.046 *$} & \multicolumn{2}{|c|}{$\mathrm{P}=0.043 *$} \\
\hline $\begin{array}{l}\mathrm{F} \text { test } \\
\text { Student-t* }\end{array}$ & \multicolumn{4}{|c|}{$\mathrm{P}=0.0001 * *$} \\
\hline Wilcoxon & \multicolumn{4}{|c|}{$\mathrm{P}=0.028 *$} \\
\hline
\end{tabular}

b) Microorganisms stamp test results of kitchen knife handle and blade

The results of the microbial stamp test (general bacteria) show in Table 3 (kitchen knife handle) and Table 4 (kitchen knife blade).

Table 3 Number of general bacteria on Kitchen knife Handle and statistical

\begin{tabular}{|c|c|c|c|c|}
\hline \multirow[b]{2}{*}{ For meat } & \multicolumn{2}{|c|}{ No alcohol treatment } & \multicolumn{2}{|c|}{ Alcohol treatment } \\
\hline & Before washing & After washing & After washing & After alcohol \\
\hline 1 & 14 & 41 & 41 & 0 \\
\hline 2 & 2 & 20 & 20 & 3 \\
\hline 3 & 123 & 150 & 150 & 16 \\
\hline 4 & 4 & 31 & 31 & 0 \\
\hline 5 & 65 & 41 & 41 & 9 \\
\hline 6 & 18 & 5 & 5 & 1 \\
\hline Average value & 37.7 & 48.0 & 48.0 & 4.8 \\
\hline SD & 47.7 & 51.8 & 51.8 & 6.4 \\
\hline F test & \multicolumn{2}{|c|}{$\mathrm{P}=0.423$} & \multicolumn{2}{|c|}{$\mathrm{P}=0.0001 * *$} \\
\hline Student- $t *$ & \multicolumn{2}{|c|}{$P=0.319$} & \multirow{2}{*}{\multicolumn{2}{|c|}{$\mathrm{P}=0.028 *$}} \\
\hline Wilcoxon & & & & \\
\hline $\begin{array}{l}\text { F test } \\
\text { Student-t* }\end{array}$ & \multicolumn{4}{|c|}{$\mathrm{P}=0.0001 * *$} \\
\hline Wilcoxon & \multicolumn{4}{|c|}{$\mathrm{P}=0.046 *$} \\
\hline
\end{tabular}

Table 4 Number of general bacteria on Kitchen knife Blade and statistical processing result

\begin{tabular}{|c|c|c|c|c|}
\hline \multirow[b]{2}{*}{ For meat } & \multicolumn{2}{|c|}{ No alcohol treatment } & \multicolumn{2}{|c|}{ Alcohol treatment } \\
\hline & Before washing & After washing & After washing & After alcohol \\
\hline 1 & 24 & 7 & 7 & 1 \\
\hline 2 & 8 & 15 & 15 & 3 \\
\hline 3 & 64 & 18 & 18 & 3 \\
\hline 4 & 32 & 40 & 40 & 32 \\
\hline 5 & 49 & 39 & 39 & 1 \\
\hline 6 & 1 & 7 & 7 & 7 \\
\hline Average value & 29.7 & 21.0 & 21.0 & 7.8 \\
\hline SD & 24.0 & 15.0 & 15.0 & 12.0 \\
\hline F test & \multicolumn{2}{|c|}{$\mathrm{P}=0.138$} & \multicolumn{2}{|c|}{$\mathrm{P}=0.305$} \\
\hline Student-t* & \multirow{2}{*}{\multicolumn{2}{|c|}{$P=0.348$}} & \multirow{2}{*}{\multicolumn{2}{|c|}{$P=0.059$}} \\
\hline Wilcoxon & & & & \\
\hline $\mathrm{F}$ test & \multicolumn{4}{|c|}{$P=0.059$} \\
\hline Student-t* & \multirow{2}{*}{\multicolumn{4}{|c|}{$P=0.108$}} \\
\hline Wilcoxon & & & & \\
\hline
\end{tabular}


The results of the microbial stamp test showed that the number of bacteria did not change much after cooking and after washing. Still, the number of bacteria decreased after spraying with70\%alcohol.

The results of the microbial stamp test (E Coli) show in Table 5 (kitchen knife handle) and Table 6 (kitchen knife blade). The results of the microbial stamp test showed that the number of bacteria changed much after cooking and after washing. But the number of bacteria did not decrease after spraying with $70 \%$ alcohol for the kitchen knife handle. The knife blade had a reduced number of microorganisms after $70 \%$ alcohol sprayings.

\begin{tabular}{|c|c|c|c|c|}
\hline \multirow[b]{2}{*}{ For meat } & \multicolumn{2}{|c|}{ No alcohol treatment } & \multicolumn{2}{|c|}{ Alcohol treatment } \\
\hline & Before washing & After washing & After washing & After alcohol \\
\hline 1 & 3 & 2 & 2 & 0 \\
\hline 2 & 2 & 8 & 8 & 27 \\
\hline 3 & 161 & 5 & 5 & 3 \\
\hline 4 & 1 & 1 & 1 & 0 \\
\hline 5 & 1 & 1 & 1 & 0 \\
\hline 6 & 0 & 0 & 0 & 6 \\
\hline Average value & 28.0 & 2.8 & 2.8 & 6.0 \\
\hline SD & 65.2 & 3.1 & 3.1 & 10.6 \\
\hline $\begin{array}{l}\mathrm{F} \text { test } \\
\text { Student-t* }\end{array}$ & \multicolumn{2}{|c|}{$\mathrm{P}=0.0001 * *$} & \multicolumn{2}{|c|}{$\mathrm{P}=0.004 * *$} \\
\hline Wilcoxon & \multicolumn{2}{|c|}{$P=0.593$} & \multicolumn{2}{|c|}{$\mathrm{P}=0.0917$} \\
\hline $\begin{array}{l}\text { test } \\
\text { Student- } t *\end{array}$ & \multicolumn{4}{|c|}{$\mathrm{P}=0.0001 * *$} \\
\hline Wilcoxon & \multicolumn{4}{|c|}{$\mathrm{P}=0.753$} \\
\hline
\end{tabular}

\begin{tabular}{|c|c|c|c|c|}
\hline \multirow[b]{2}{*}{ For meat } & \multicolumn{2}{|c|}{ No alcohol treatment } & \multicolumn{2}{|c|}{ Alcohol treatment } \\
\hline & Before washing & After washing & After washing & After alcohol \\
\hline 1 & 2 & 2 & 2 & 1 \\
\hline 2 & 1 & 0 & 0 & 1 \\
\hline 3 & 163 & 60 & 60 & 0 \\
\hline 4 & 0 & 0 & 0 & 0 \\
\hline 5 & 2 & 1 & 1 & 0 \\
\hline 6 & 0 & 0 & 0 & 0 \\
\hline Average value & 28.0 & 10.5 & 10.5 & 0.3 \\
\hline SD & 66.1 & 24.3 & 24.3 & 0.5 \\
\hline $\begin{array}{l}\text { I test } \\
\text { Student-t* }\end{array}$ & \multicolumn{2}{|c|}{$\mathrm{P}=0.014 *$} & \multicolumn{2}{|c|}{$\mathrm{P}=0.0001 * *$} \\
\hline $\begin{array}{l}\text { Student-t* } \\
\text { Wilcoxon }\end{array}$ & & \\
\hline $\begin{array}{l}F \text { test } \\
\text { Student-t* }\end{array}$ & \multicolumn{4}{|c|}{$\mathrm{P}=0.0001 * *$} \\
\hline Wilcoxon & \multicolumn{4}{|c|}{$P=0.109$} \\
\hline
\end{tabular}

The results of the microbial stamp test (Staphylococcus aureus) show in Table 7 (kitchen knife handle) and Table 8 (kitchen knife blade). The results of the microbial stamp test showed that the number of bacteria did not change much after cooking and after washing,. Still, the number of bacteria decreased after spraying with $70 \%$ alcohol.

Table 7 Number of Staphylococcus aureus on Kitchen knife Handle and statistical

\begin{tabular}{|c|c|c|c|c|}
\hline \multirow[b]{2}{*}{ For meat } & \multicolumn{2}{|c|}{ No alcohol treatment } & \multicolumn{2}{|c|}{ Alcohol treatment } \\
\hline & Before washing & After washing & After washing & After alcohol \\
\hline 1 & 9 & 1 & 1 & 0 \\
\hline 2 & 7 & 9 & 9 & 5 \\
\hline 3 & 0 & 1 & 1 & 10 \\
\hline 4 & 0 & 1 & 1 & 2 \\
\hline 5 & 26 & 1 & 1 & 70 \\
\hline 6 & 9 & 12 & 12 & 11 \\
\hline Average value & 8.5 & 4.2 & 4.2 & 16.3 \\
\hline SD & 9.5 & 5.0 & 5.0 & 26.6 \\
\hline F test & \multicolumn{2}{|c|}{$\mathrm{P}=0.071$} & \multicolumn{2}{|c|}{$\mathrm{P}=0.0001 * *$} \\
\hline Student- $t *$ & \multicolumn{2}{|c|}{$P=0.374$} & \multirow{2}{*}{\multicolumn{2}{|c|}{$P=0.600$}} \\
\hline Wilcoxon & & & & \\
\hline $\mathrm{F}$ test & \multirow{2}{*}{\multicolumn{4}{|c|}{$\mathrm{P}=0.012 *$}} \\
\hline Student- $t *$ & & & & \\
\hline Wilcoxon & \multicolumn{4}{|c|}{$P=0.345$} \\
\hline
\end{tabular}


Table 8 Number of Staphylococcus aureus on Kitchen knife Blade and statistical

\begin{tabular}{|c|c|c|c|c|}
\hline \multirow[b]{2}{*}{ For meat } & \multicolumn{2}{|c|}{ No alcohol treatment } & \multicolumn{2}{|c|}{ Alcohol treatment } \\
\hline & Before washing & After washing & After washing & After alcohol \\
\hline 1 & 21 & 0 & 0 & 0 \\
\hline 2 & 30 & 136 & 136 & 0 \\
\hline 3 & 1 & 250 & 250 & 2 \\
\hline 4 & 117 & 2 & 2 & 0 \\
\hline 5 & 29 & 4 & 4 & 0 \\
\hline 6 & 0 & 3 & 3 & 0 \\
\hline Average value & 33.0 & 65.8 & 65.8 & 0.3 \\
\hline SD & 43.2 & 104.9 & 104.9 & 0.8 \\
\hline F test & \multicolumn{2}{|c|}{$\mathrm{P}=0.024 *$} & \multicolumn{2}{|c|}{$\mathrm{P}=0.0001 * *$} \\
\hline \multicolumn{5}{|l|}{ Student- $t *$} \\
\hline Wilcoxon & \multicolumn{2}{|c|}{$\mathrm{P}=0.917$} & \multicolumn{2}{|c|}{$\mathrm{P}=0.043 *$} \\
\hline $\mathrm{F}$ test & \multicolumn{4}{|c|}{$\mathrm{P}=0.0001 * *$} \\
\hline \multicolumn{5}{|l|}{ Student- $t *$} \\
\hline Wilcoxon & \multicolumn{4}{|c|}{$P=0.080$} \\
\hline
\end{tabular}

The results of the microbial stamp test (Salmonella) show in Table 9 (kitchen knife handle) and Table 10 (kitchen knife blade). The results of the microbial stamp test showed that the number of bacteria changed much after cooking and after washing. And the number of bacteria decreased after spraying with $70 \%$ alcohol.

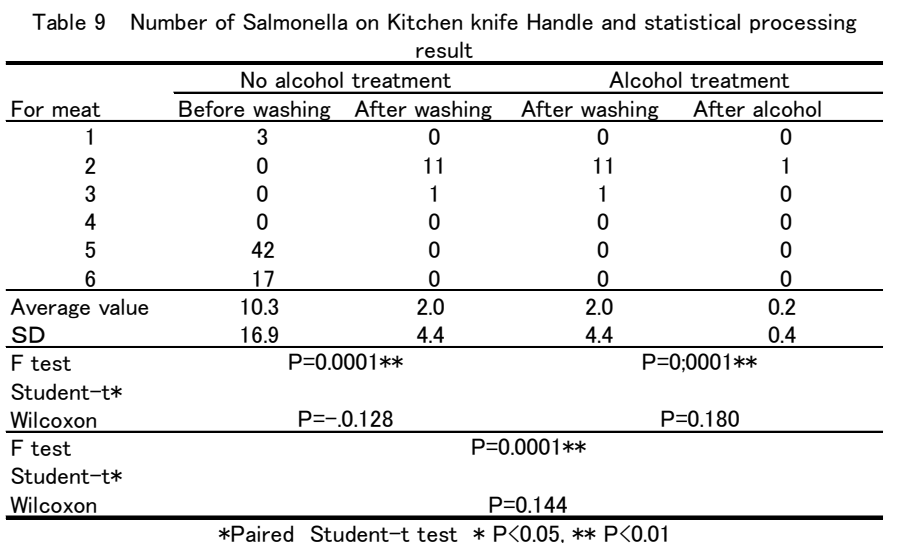

Table 10 Number of Salmonella on Kitchen knife Blade. and statistical processing

\begin{tabular}{|c|c|c|c|c|}
\hline \multirow[b]{2}{*}{ For meat } & \multicolumn{2}{|c|}{ No alcohol treatment } & \multicolumn{2}{|c|}{ Alcohol treatment } \\
\hline & Before washing & After washing & After washing & After alcohol \\
\hline 1 & 2 & 0 & 0 & 0 \\
\hline 2 & 24 & 5 & 5 & 1 \\
\hline 3 & 0 & 0 & 0 & 0 \\
\hline 4 & 1 & 0 & 0 & 0 \\
\hline 5 & 47 & 1 & 1 & 0 \\
\hline 6 & 25 & 0 & 0 & 0 \\
\hline Average value & 16.5 & 1.0 & 1.0 & 0.2 \\
\hline SD & 18.9 & 2.0 & 2.0 & 0.4 \\
\hline $\begin{array}{l}\mathrm{F} \text { test } \\
\text { Student-t* }\end{array}$ & \multicolumn{2}{|c|}{$\mathrm{P}=0.0001 * *$} & \multicolumn{2}{|c|}{$\mathrm{P}=0.001 * *$} \\
\hline Wilcoxon & \multicolumn{2}{|c|}{$\mathrm{P}=0.43 *$} & \multicolumn{2}{|c|}{$\mathrm{P}=0.180$} \\
\hline F test & \multicolumn{4}{|c|}{$\mathrm{P}=0.0001 * *$} \\
\hline $\begin{array}{l}\text { Student-t* } \\
\text { Wilcoxon }\end{array}$ & \multicolumn{4}{|c|}{$\mathrm{P}=0.043 *$} \\
\hline
\end{tabular}

The results of the microbial stamp test (Vibrio parahaemolyticus) show in Table 11 (kitchen knife handle) and Table 12 (kitchen knife blade). The results of the microbial stamp test showed that the number of bacteria changed much after cooking and after washing. And the number of bacteria decreased after spraying with $70 \%$ alcohol. 
Table 11 Number of Vibrio parahaemolyticus on Kitchen knife Handleand statistical

\begin{tabular}{|c|c|c|c|c|}
\hline \multirow[b]{2}{*}{ For meat } & \multicolumn{2}{|c|}{ No alcohol treatment } & \multicolumn{2}{|c|}{ Alcohol treatment } \\
\hline & Before washing & After washing & After washing & After alcohol \\
\hline 1 & 0 & 0 & 0 & 0 \\
\hline 2 & 0 & 27 & 27 & 0 \\
\hline 3 & 102 & 0 & 0 & 0 \\
\hline 4 & 0 & 0 & 0 & 2 \\
\hline 5 & 37 & 1 & 1 & 3 \\
\hline 6 & 0 & 0 & 0 & 1 \\
\hline Average value & 23.2 & 4.7 & 4.7 & 1.0 \\
\hline SD & 41.4 & 10.9 & 10.9 & 1.3 \\
\hline $\begin{array}{l}\mathrm{F} \text { test } \\
\text { Student-t* }\end{array}$ & \multicolumn{2}{|c|}{$\mathrm{P}=0.003 * *$} & \multicolumn{2}{|c|}{$\mathrm{P}=0.0001 * *$} \\
\hline Wilcoxon & \multicolumn{2}{|c|}{$\mathrm{P}=0.285$} & \multicolumn{2}{|c|}{$\mathrm{P}=0.715$} \\
\hline $\begin{array}{l}\mathrm{F} \text { test } \\
\text { Student-t* }\end{array}$ & \multicolumn{4}{|c|}{$\mathrm{P}=0.0001 * *$} \\
\hline Wilcoxon & \multicolumn{4}{|c|}{$P=0.465$} \\
\hline
\end{tabular}

Table 12 Number of Vibrio parahaemolyticus on Kitchen knife Blade and statistical processing result

\begin{tabular}{|c|c|c|c|c|}
\hline \multirow[b]{2}{*}{ For meat } & \multicolumn{2}{|c|}{ No alcohol treatment } & \multicolumn{2}{|c|}{ Alcohol treatment } \\
\hline & Before washing & After washing & After washing & After alcohol \\
\hline 1 & 1 & 0 & 0 & 0 \\
\hline 2 & 0 & 0 & 0 & 0 \\
\hline 3 & 1 & 1 & 1 & 0 \\
\hline 4 & 0 & 0 & 0 & 0 \\
\hline 5 & 0 & 0 & 0 & 0 \\
\hline 6 & 4 & 1 & 1 & 1 \\
\hline Average value & 1.0 & 0.3 & 0.3 & 0.2 \\
\hline SD & 1.5 & 0.5 & 0.5 & 0.4 \\
\hline $\mathrm{F}$ test & \multicolumn{2}{|c|}{$\mathrm{P}=0.009 * *$} & \multicolumn{2}{|c|}{$\mathrm{P}=0.291$} \\
\hline Student- $\mathrm{t} *$ & & \multirow{2}{*}{\multicolumn{2}{|c|}{$P=363$}} \\
\hline Wilcoxon & \multicolumn{2}{|c|}{$\mathrm{P}=0.180$} & & \\
\hline $\mathrm{F}$ test & \multirow{2}{*}{\multicolumn{4}{|c|}{$\mathrm{P}=0.002 * *$}} \\
\hline Student- $t *$ & & & & \\
\hline Wilcoxon & \multicolumn{4}{|c|}{$\mathrm{P}=0.109$} \\
\hline
\end{tabular}

\section{Discussion}

In the previous research report, we were able to reduce the ATP value to 100 or less by washing the handle and blade of the knife with running water for 30 seconds or more ${ }^{1)}$. This time, we further examined hygiene management using alcohol to protect the safety and security of meals, even in an environment where COVID-19 is prevalent. It is costly to manage the hygiene of the handle and blade of the kitchen knife using $70 \%$ alcohol, but we thought that it would be safer. In addition to the ATP test, a microbial stamp test was also performed at the same time to confirm whether food poisoning bacteria were reduces. As a result, in most cases, the number of bacteria decreased after spraying $70 \%$ alcohol as compared with after washing. In Escherichia coli (E. Coli) and Staphylococcus aureus, the number of bacteria increased after $70 \%$ alcohol sprayings on the knife blade compared with after washing. We think it is necessary to spray alcohol more firmly. Many reports have been made on ATP wiping tests for hospital meals $\mathrm{s}^{2,3)}$ and business meals ${ }^{4,5)}$. Hygiene education is provided by instructing cooks on the hygienic handling of cooking utensils ${ }^{6,7)}$. In addition to the ATP wiping test ${ }^{8,9)}$, we believe that cooking utensils can handle more hygienically by conducting a microbial stamp test at the same time.

\section{Conclusions}

Microbial tests performed on the handles and blades of kitchen knives in kitchens where hygienic handling is required, after cooking, cleaning, and spraying with $70 \%$ alcohol. ATP wiping test and microbial stamp test used for the test. As a result, it found that the number of microorganisms decreased after $70 \%$ alcohol spraying, but E. Coli and Staphylococcus aureus did not decrease simply. In the future, we would like to report the results of sterilizing the handle and blade of the kitchen knife by spraying70\% alcohol more firmly.

\section{AcKNOWLeDgments}

We would like to thank all the cooks who participated in this experiment. Also, we would like to thank the inspectors who also performed the ATP inspection.

\section{References Références Referencias}

1. Katayama N, Ito A, Hirabayashi M, Kondo S, Nakayama Y, Naka A, Aasaki N, Inuzuka M, Tamura T. Results of Hygiene Education of Kitchen Knife by using ATP Inspection -Comparison of Handle and Blade: (2020) Global Journals Medical Research 20(5): $1-6$.

2. Nante $N$, Ceriale E, Messina G, Lenzi D, Manzi P. Effectiveness of ATP bioluminescence to assess 
hospital cleaning: a review. (2017) J Prev. Med. Hyg. 58(2): E177-E183.

3. Amodio E, Dubi C. Use of ATP bioluminescence for assessing heclealiness of hospital surfaces: a review of the published literature (1990-2012).(2014) $\mathrm{J}$ infect Public Health 7(2): 92-98.

4. Aycieck H, Oquz U. Karci K. Comparison of results of ATP bioluminescence and traditional ygiene swabbing methods for the deteminaton of surface cleanliness at a hospital kitchen. (2006). Int J Hyg Environ Heatth. 209(2): 203-206.

5. Osimani A, Garofalo C, Clementi F, Tavoletti S, Aquilanti L.Bioluminescence ATP monitoring for the routine assessment of food contact surface cleanliness in a university canteen. (2014). Int J Environ Res Public Health 17; 11(10): 10824-10837.

6. Lee JH (2018) An investigation of Factors that influence Hygiene Practices at a small Day Care Center. (2018). J Food Prot. 81(1): 158-164.

7. Stanley PE. A review of bioluminescent STP techniques in papid microbiology. (1989) J Biolumin Chemilumin 4(1): 375-380.

8. Griffith CJ, Coooper RA, Gilmore J, Davies C, Lweis $M$. An evaluation of hospital cleaning refimes and standards. (2000) J Hosp Infect. 45(1): 19-28.

9. Stannard CJ, Gibbs PA. Rapid microbiology: applications of bioluminescence in the food industry-a review. (1986) J Biolumin Chemilumin 1(1): 3-10. 